\title{
Evaluation of a Herbicide-resistant Trait Conferred by the Bar Gene Driven by Four Distinct Promoters in Transgenic Blueberry Plants
}

\author{
Guo-Qing Song ${ }^{1}$, Kenneth C. Sink, Peter W. Callow, Rebecca Baughan, and James F. Hancock \\ Plant Biotechnology Resource and Outreach Center, Department of Horticulture, Michigan State \\ University, East Lansing, MI 48824
}

\begin{abstract}
AdDitional INDEX words. glufosinate ammonium, small fruit crop, transgene expression, Vaccinium corymbosum, woody plant

Abstract. Four chimeric bialaphos resistance (bar) genes driven by different promoters were evaluated for production of herbicide-resistant 'Legacy' blueberry plants $(\mathbf{7 3 . 4 \%}$ Vaccinium corymbosum L. and $25 \%$ Vaccinium darrowi Camp) through Agrobacterium tumefaciens (Smith \& Towns.) Conn.-mediated transformation. When the bars were used as selectable marker genes, different promoters yielded different transformation frequencies. Three chimeric bar genes with the promoter nopaline synthase (nos), cauliflower mosaic virus (CaMV) 35S, or CaMV 34S yielded transgenic plants, whereas a synthetic (Aocs) ${ }_{3}$ AmasPmas promoter did not lead to successful regeneration of transgenic plants. In addition, herbicide resistance in bar-expressing plants was influenced by the promoter strength. Under controlled environmental conditions, 3-month-old plants from six single-copy transgenic events with 35S::bar or nos::bar, as well as those nontransgenic plants, were sprayed with herbicide glufosinate ammonium (GS) at five levels $\left(0,750,1500,3000\right.$, and $\left.6000 \mathrm{mg} \cdot \mathrm{L}^{-1}\right)$. Evaluations on leaf damage 2 weeks after spraying indicated that all transgenic plants exhibited much higher herbicide resistance than nontransgenic plants. Additionally, the transgenic plants with the $355::$ bar showed a higher herbicide resistance than those with the nos::bar. After application of 6000 $\mathrm{mg} \cdot \mathrm{L}^{-1} \mathrm{GS}$, over $90 \%$ of the leaves from plants with the $35 \mathrm{~S}::$ bar and $19.5 \%$ to $51.5 \%$ of the leaves from plants with the nos::bar showed no symptom of herbicide damage, whereas only $5 \%$ of leaves from the nontransgenic had no damage. One-year-old, field-grown plants from four transgenic events with the nos::bar were evaluated for herbicide resistance after spraying with $750 \mathrm{mg} \cdot \mathrm{L}^{-1} \mathrm{GS}$. Transgenic plants survived with variations in the level of foliar damage; in contrast, all nontransgenic plants died. This study is the first investigation of different promoters for engineering transgenic blueberry plants.
\end{abstract}

Blueberry is an important fruit crop in the genus Vaccinium L. (for reviews, see Ratnaparkhe 2007; Song and Sink, 2005). Blueberry fruit are one of the richest sources of antioxidant phytonutrients among the fresh fruit (Conner et al., 2002; Ehlenfeldt and Prior, 2001). According to U.S. Department of Agriculture-National Agricultural Statistics Service (USDA, 2007), the United States ranks first in world production of blueberry, supplying $124,976 \mathrm{Mg}$ of blueberry fruit on 21,376 ha in 2006.

Molecular genetic and genomic approaches will enable localization and isolation of genes controlling blueberry traits such as fruit size, fruit quality, disease resistance, and various environmental tolerances. Recently, several genes associated with cold hardiness have been identified and isolated from highbush blueberry using a large expressed sequence tag library, forward and reverse subtracted cDNA libraries, or microarrays (Dhanaraj et al., 2004, 2007; Naik et al., 2007). Once genes of interest are isolated, genetic engineering and transformation of blueberry will be a powerful approach to

Received for publication 19 Feb. 2008. Accepted for publication 7 Apr. 2008. This research was supported by Michigan State University Project GREEEN (Generating Research and Extension to Meet Economic and Environmental Needs).

We thank Dr. Detlef Becker (Max Planck Institut, Germany) for providing plasmid pGPTV-BAR, Dr. D. Bouchez (INRA, France) for providing plasmid pDHB321.1, Dr. S.B. Gelvin (Purdue University) for providing the plasmids containing the (Aocs) ${ }_{3}$ AmasPmas promoter, and Drs. Eric J. Hanson and Bernard H. Zandstra for their help with herbicide application.

${ }^{1}$ Corresponding author. E-mail: songg@msu.edu. complement traditional breeding by rapidly introducing individual traits without changing the inherent desirable characteristics of existing cultivars (Ratnaparkhe, 2007; Song and Sink, 2005). To date, transformation methodologies for blueberry cultivars have been developed by several research groups (Cao et al., 1998, 2003; Graham et al., 1996; Rowland, 1990; Song and Sink, 2004, 2006; Song et al., 2007a).

There are some particularly persistent perennial weeds adapted to low $\mathrm{pH}$ soils of blueberry fields. To control weeds, nonselective and broad-spectrum herbicides, such as glyphosate and glufosinate ammonium, are preferable; however, they can be applied only as a directed spray under the bushes to avoid contact with green tissues. Blueberry plants withstanding broad-spectrum herbicides would add flexibility to weed control programs while providing a simple and effective management tool. Broad-spectrum herbicide resistance genes have been introduced into many crop species (Castle et al., 2004; James, 2007). In 2006, herbicide tolerance, deployed in soybean [Glycine $\max (\mathrm{L}$.) Merr.], maize (Zea mays L.), canola (Brassica napus L.), cotton (Gossypium L.), and alfalfa (Medicago sativa L.) continued to be the most dominant trait, occupying 68\% (69.9 million hectares) of global biotechnology crops (James, 2007). In Vaccinium species, transformed cranberry (Vaccinium macrocarpon Ait.) plants with the bialaphos resistance gene (bar) showed resistance to $1000 \mathrm{mg} \cdot \mathrm{L}^{-1} \mathrm{GS}$ (Polashock and Vorsa, 2002). Using our established transformation protocol (Song and Sink, 2005), four constructs, including nos::bar, 35S::bar, (Aocs) ${ }_{3}$ AmasPmas::bar, and $34 S:: b a r$ were previously used to produce herbicide-resistant 


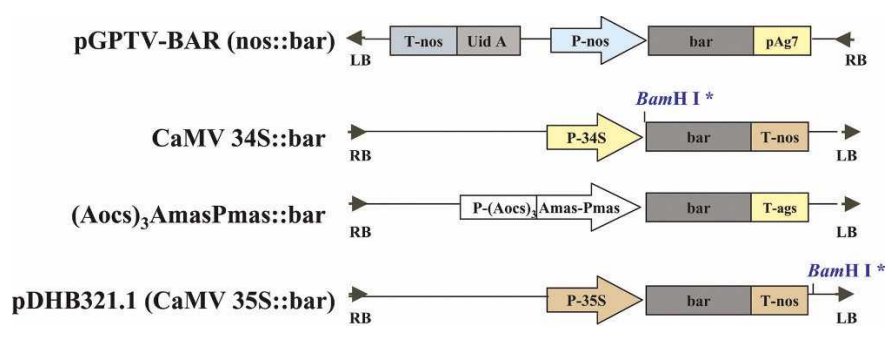

Fig. 1. Schematic representation of the transfer DNA (T-DNA) region of the four bialaphos resistance $($ bar $)$ gene constructs. T-nos $=$ nos gene terminator, $\mathrm{pAg} 7=$ gene7 $(p \mathrm{Ag} 7)$ polyadenylation signal, $\mathrm{P}-\mathrm{nos}=$ nopaline synthase $($ nos $)$ promoter, bar = bar gene coding region, $\mathrm{P}-34 \mathrm{~S}=$ cauliflower mosaic virus $(\mathrm{CaMV}) 34 \mathrm{~S}$ promoter, $\mathrm{P}-(\text { Aocs })_{3}$ AmasPmas $=(\text { Aocs })_{3}$ AmasPmas promoter, $\mathrm{T}$-ags $=$ agropine synthase $($ ags $)$ terminator, $\mathrm{P}-35 \mathrm{~S}=\mathrm{CaMV} 35 \mathrm{~S}$ promoter, $\mathrm{HPT}=$ hygromycin phosphotransferase coding region, $\mathrm{RB}=$ right $\mathrm{T}-\mathrm{DNA}$ border, $\mathrm{LB}=$ left T-DNA border, $\mathrm{Bam} \mathrm{HI}=$ unique restriction endonucleases at T-DNA region.

Table 1. Summary of transformations of 'Legacy' blueberry using the bialaphos resistance (bar) gene driven by different promoters.

\begin{tabular}{|c|c|c|c|c|c|}
\hline Construct $^{\mathrm{z}}$ & $\begin{array}{l}\text { Explants } \\
\text { inoculated } \\
\text { (no.) }\end{array}$ & $\begin{array}{c}\text { Explants } \\
\text { yielding } \\
\text { shoots with } \\
\text { resistance to } \\
0.1 \mathrm{mg} \cdot \mathrm{L}^{-1} \\
\mathrm{GS}^{\mathrm{y}} \text { (no.) }\end{array}$ & $\begin{array}{c}\text { Explants } \\
\text { yielding } \\
\text { shoots with } \\
\text { resistance to } \\
0.5 \mathrm{mg} \cdot \mathrm{L}^{-1} \\
\text { GS (no.) }\end{array}$ & $\begin{array}{c}\text { Explants } \\
\text { yielding } \\
\text { PCR- } \\
\text { positive } \\
\text { shoots (no.) }\end{array}$ & $\begin{array}{c}\text { Avg } \\
\text { transformation } \\
\text { frequency } \\
(\% \pm \mathrm{SD})\end{array}$ \\
\hline $35 S:: b a r$ & 202 & 32 & 16 & 16 & $7.9 \pm 0.6$ \\
\hline $34 S:: b a r$ & 201 & 6 & 3 & 3 & $1.5 \pm 0.6$ \\
\hline (Aocs) ${ }_{3}$ AmasPmas $:$ bar & 209 & 8 & 0 & 0 & $0.0 \pm 0.0$ \\
\hline Nos::bar & 300 & 30 & 21 & 21 & $7.0 \pm 2.2$ \\
\hline
\end{tabular}

${ }^{\mathrm{z}} 35 \mathrm{~S}=$ cauliflower mosaic virus $(\mathrm{CaMV}) 35 \mathrm{~S}$ promoter, $34 \mathrm{~S}=$ CaMV 34S promoter, $(\text { Aocs })_{3}$ AmasPmas $=(\text { Aocs })_{3}$ AmasPmas promoter, Nos $=$ nos gene promoter.

${ }^{\mathrm{y}} \mathrm{GS}=$ glufosiante ammonium.

${ }^{\mathrm{x}}$ Based on results of PCR amplification of the presence of the bar for the shoots showing resistance to 0.5 $\mathrm{mg} \cdot \mathrm{L}^{-1} \mathrm{GS}$. Transformation frequency $=$ number of leaf explants with at least one PCR-positive shoot/ total number of inoculated explants $\times 100$.

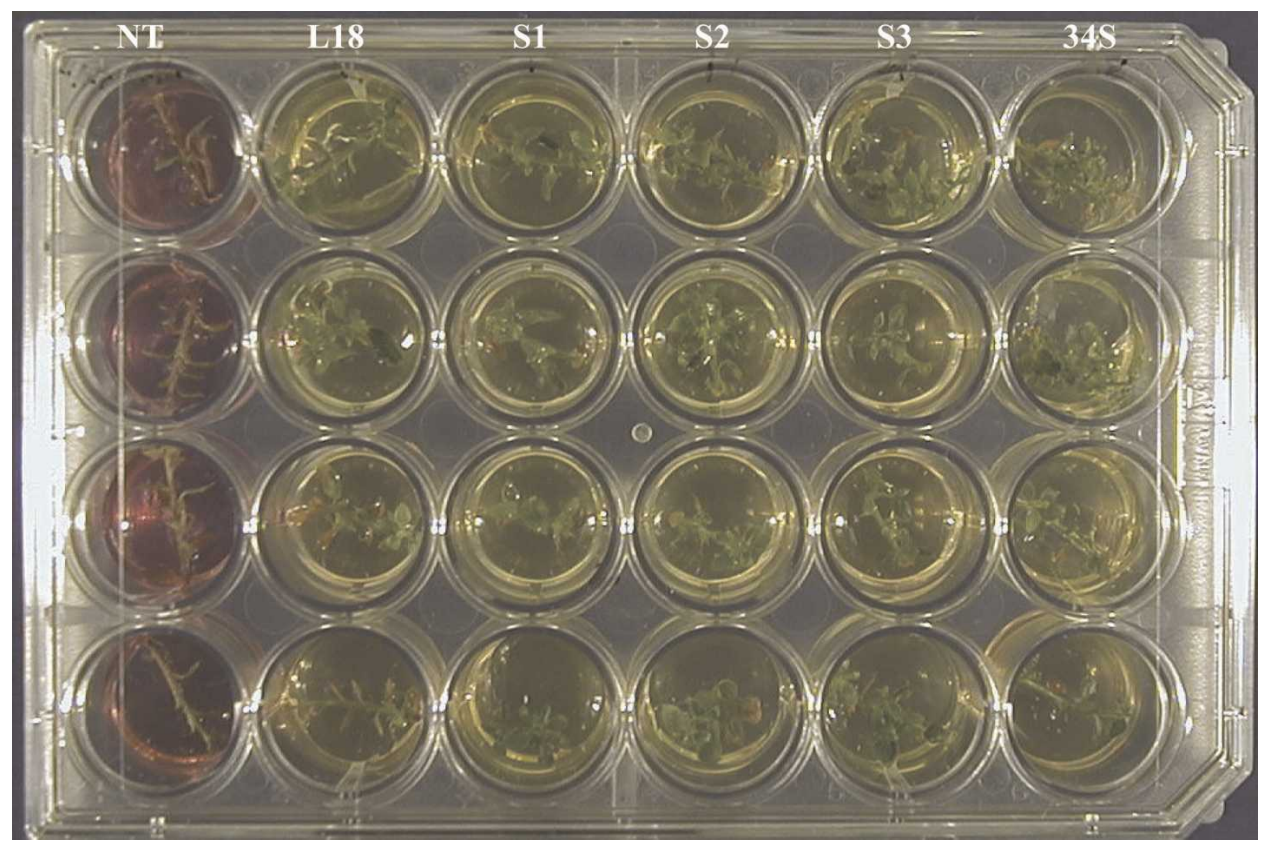

Fig. 2. 'Legacy' blueberry shoots on chlorophenol red assay medium after 2 weeks. NT = nontransgenic shoots; $\mathrm{L} 18=$ a representative transgenic clone with the $n o s::$ bar; S1, S2, and S3 = transgenic clones with the $35 S: \because$ bar; $34 \mathrm{~S}=$ a transgenic clone with the $34 \mathrm{~S}:$ :bar. blueberry plants. Our preliminary results demonstrated that the nos::bar gene can serve as a selectable marker for transation, as well as being a source for herbicide resistance influenced by promoters and the host plant species (Ni et al., Song et al., 2007b; Wilmink et al., 1995). Evaluation of promoters for genetic engineering blueberry plants blueberry plants and to test their effect on herbicide resistance

\section{Materials and Methods}

CONSTRUCTS AND AGROBACTERIUM STRAIN. Four bar-containing vectors were used (Fig. 1). PGPTV-BAR (a gift from D. Becker, Max-Planck-Institut, Köln, Germany) has bar under the nos promoter and gene7 ( $\mathrm{pAg} 7)$ polyadenylation signal (Becker et al., 1992). PDHB321.1 (a gift from D. Bouchez, Institut National de la Recherche Agronomique, Versailles, France) contains the bar gene under the $35 \mathrm{~S}$ promoter and the nos terminator. A polymerase chain reaction (PCR)amplified 5'-HindIII-bar-XbaI-3' fragment covering the coding region of bar was inserted into multiple cloning sites located between (Aocs) AmasPmas promoter and an agropine synthase (ags) terminator in pUC119 to generate a bar expression cassette (Aocs) ${ }_{3}$ Amas Pmas::bar::ags. Similarly, a PCR-amplified 5'-HindIIIbar-XbaI-3' fragment was inserted into multiple cloning sites located in front of the nos terminator in pUC19 to yield a cloning vector with multiple cloning sites plus bar::nos. Subsequently, a 5'-BamHI (blunted)bar-nos-EcoRI-3' fragment was

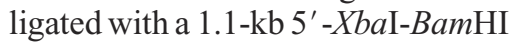
(blunted)-3' fragment, derived from pMS34b, containing the cauliflower mosaic virus (CaMV) $34 \mathrm{~S}$ promoter. The 5'-XbaI-34S::bar::nos-EcoRI3 ' fragment derived was inserted into multiple cloning sites of pUC19 to create a bar expression cassette. The HindIII (blunted)$34 S:: b a r:: n o s-S m a \mathrm{I}$ and PvuII(Aocs) ${ }_{3}$ AmasPmas: :bar::ags-PvuII were then inserted into the blank TDNA region of pGPTV-BAR at $E c o$ RI (blunted)-XmnI, respectively, to generate vectors with bar expression cassettes. All plasmids were checked by restriction mapping and the PCR-amplified bar was confirmed by sequencing. 


\begin{tabular}{|l|l|l|l|l|l|}
\hline S1 & S2 & NT & S3 & 34 S & M \\
\hline
\end{tabular}

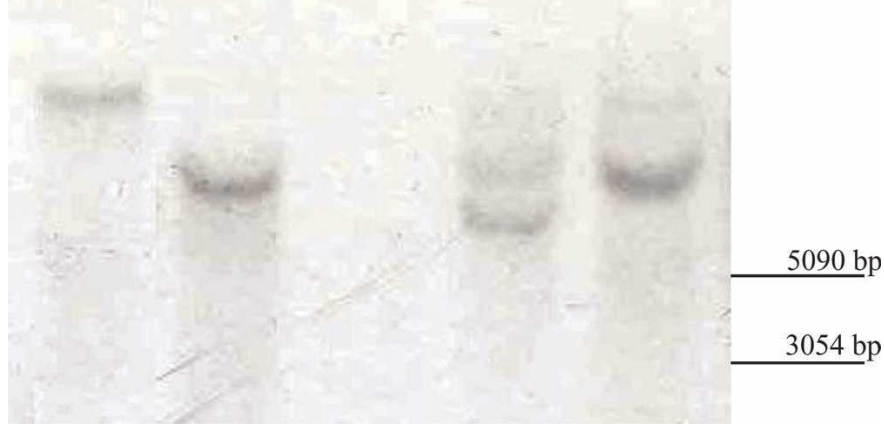

Fig. 3. Southern hybridizations for the bialaphos resistance (bar) gene in blueberry plants. DNA samples were digested with BamHI and hybridized with a 438-bp fragment containing the bar coding region. NT = nontransgenic plant; S1, S2, and S3 = transgenic events with the $35 S: \because$ bar; $34 \mathrm{~S}=$ transgenic event with the $34 S: \because$ bar; $\mathrm{M}=$ molecular marker.

All four bar-containing vectors were introduced into $A$. tumefaciens strain EHA105 using the freeze-thaw transformation method (An et al., 1988; Hood et al., 1993).

Plant transformation. Transformation of 'Legacy' blueberry using four bar-containing vectors was performed according to our previous reports (Song and Sink, 2006). For each
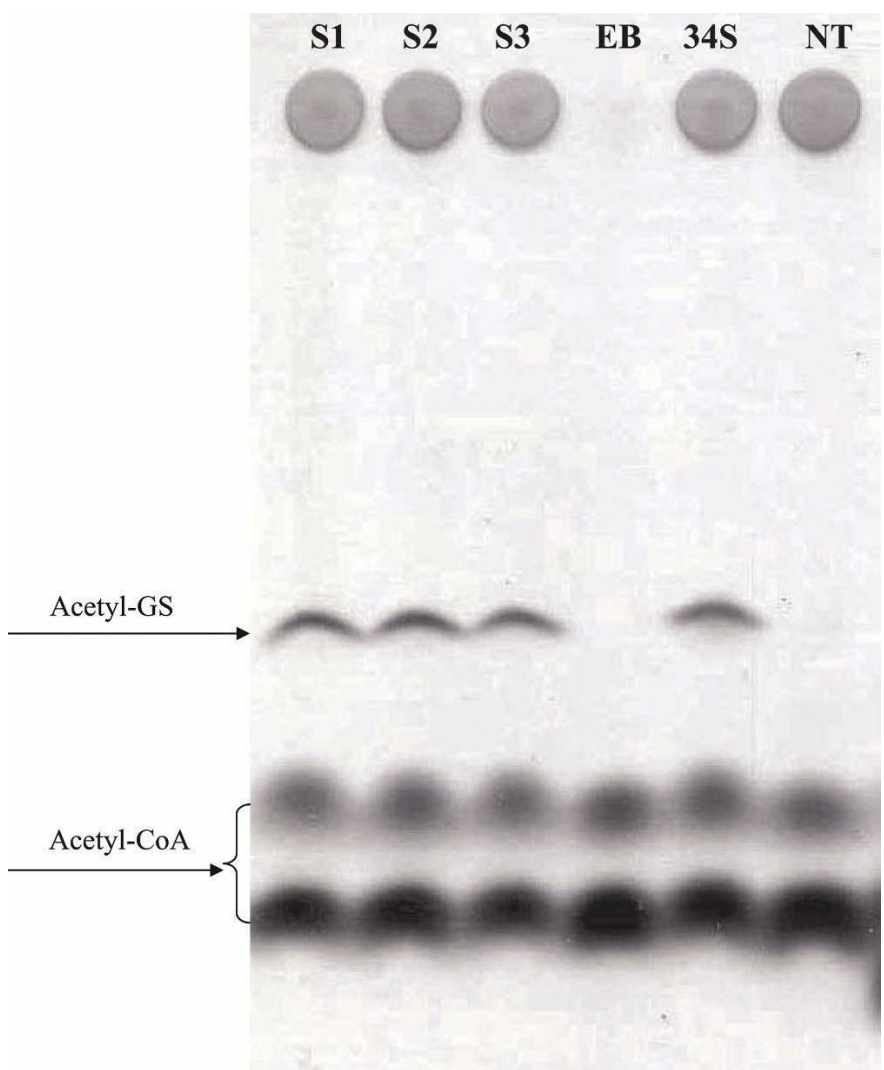

Fig. 4. PAT activity in leaf extracts of transgenic blueberry. Glufosinate ammonium (GS) is acetylated by the bialaphos resistance (bar) gene product under the presence of acetyl-coenzyme A, yielding acetyl-GS. S1, S2, and S3 = three transgenic events with the $35 \mathrm{~S}::$ bar; $\mathrm{EB}=$ extract buffer for crude protein extract; $34 \mathrm{~S}=$ transgenic event with the $34 \mathrm{~S}: \because$ bar $; \mathrm{NT}=$ nontransgenic plant. vector, 200 to 300 leaf explants were used in two transformation experiments. The number of regenerating explants was recorded after 10 weeks. Morphologically normal-appearing plants of three events transformed with $35 S: \because$ bar and one event

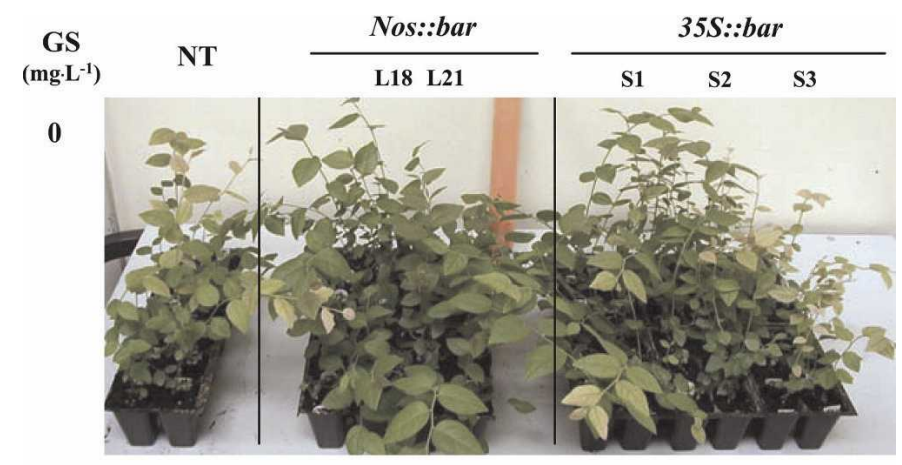

750

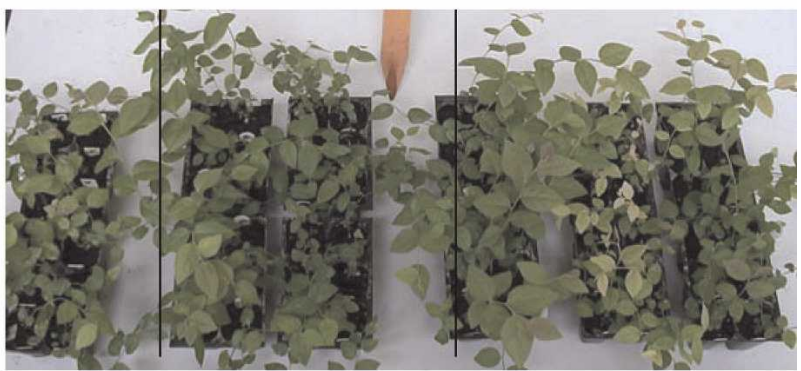

1500

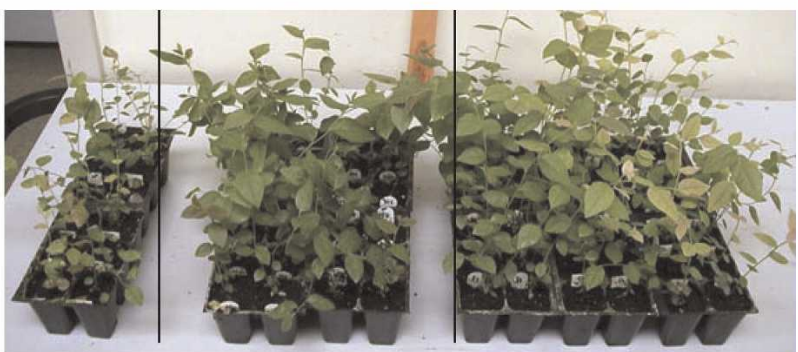

3000

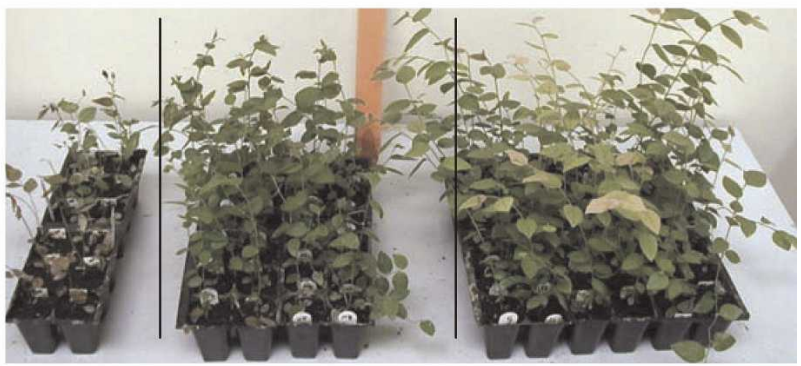

6000

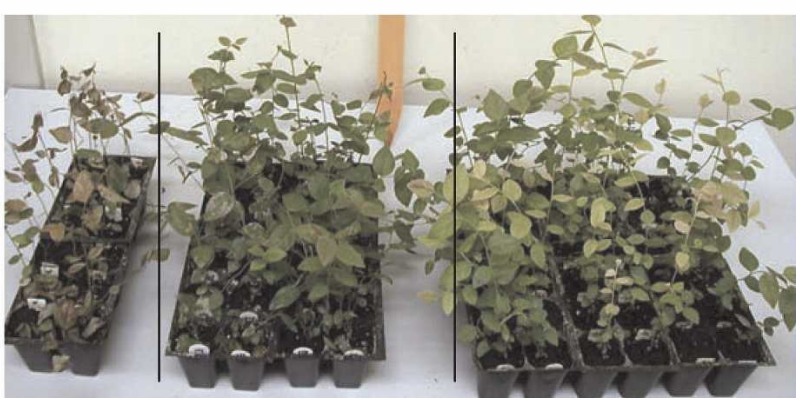

Fig. 5. Response of 'Legacy' blueberry plants 2 weeks after application of four levels $\left(750,1500,3000\right.$, and $\left.6000 \mathrm{mg} \cdot \mathrm{L}^{-1}\right)$ of herbicide glufosinate under controlled environmental conditions. NT = nontransgenic blueberry; S1, S2, and S3 = transgenic events with the $35 \mathrm{~S}: \because$ bar; L18 and L21 = transgenic events each with a single copy of the nos::bar. 
with $34 S: \because b a r$ were selected and subjected to the chlorophenol red (CR) assay, Southern blot analysis, and phosphinothricin acetyltransferase (PAT) assay. Transgenic events with nos::bar were previously reported using these assays (Song et al., 2007a).

Chlorophenol red assay. CR assay was performed according to our previous report (Song et al., 2007a). Nontransgenic and transgenic shoots, 0.8 to $1.2 \mathrm{~cm}$ in length, were placed individually into wells of a $24-$ well $(6 \times 8)$ microliter plate containing $1 \mathrm{~mL}$ of assay medium. The plates were placed at $25{ }^{\circ} \mathrm{C}$ under a $16-\mathrm{h}$ photoperiod of $50 \mu \mathrm{mol} \cdot \mathrm{m}^{-2} \cdot \mathrm{s}^{-1}$ and were inoculated for 2 weeks.

SOUTHERN BLOT ANALYSIS. Total DNA was isolated from $2 \mathrm{~g}$ of fresh leaf tissue of newly obtained transgenic events by the CTAB method (Doyle and Doyle, 1987). BamHIdigested DNA, $20 \mu \mathrm{g}$ per sample, was electrophoresed in a $0.8 \%$ agarose gel and was then transferred to $\mathrm{N}^{+}$-nylon membranes (Amersham, Arlington Heights, IL). A 438-bp fragment containing the bar coding region was used as the probe after labeling with $\left[{ }^{32} \mathrm{P}\right]$-dCTP using Random Primers DNA Labeling System (Invitrogen, Carlsbad, CA). Hybridization and membrane washing was conducted according to our previous report (Song and Sink, 2004).

PhOSPHINOTHRICIN ACETYLTRANSFERASE ASSAY. Crude protein was extracted as described (De Block et al., 1987) from $200 \mathrm{mg}$ of leaf tissue. The protein was quantified using a protein assay reagent (Bio-Rad Laboratories, Hercules, CA). The PAT reaction mixture $(20 \mu \mathrm{L}: 50 \mathrm{~mm}$ Tris-HCL, $5.6 \mathrm{~mm}^{14} \mathrm{C}$ acetyl-CoA, $100 \mu \mathrm{M}$ GS, and $30 \mu \mathrm{g}$ of sample protein) was incubated at $37^{\circ} \mathrm{C}$ for 30 min, spotted $(10 \mu \mathrm{L})$ onto a silica gel thin-layer chromatography plate, and separated by ascending chromatography in a $3: 2(\mathrm{v} / \mathrm{v})$ mixture of 1-propanol and $\mathrm{NH}_{4} \mathrm{OH}$ (De Block et al., 1987). ${ }^{14} \mathrm{C}$ was visualized by autoradiography.

HERBICIDE RESISTANCE IN PLANTS GROWN UNDER CONTROLLED ENVIRONMENTAL CONDITIONS. One-month-old rooted plants were grown in planting medium (sphagnum moss:soil $=1: 1, \mathrm{v} / \mathrm{v}$ ) in six-cell trays. They were watered as needed, fertilized weekly using $0.2 \mathrm{~g} \cdot \mathrm{L}^{-1} 21 \mathrm{~N}-3.1 \mathrm{P}-5.8 \mathrm{~K}$ fertilizer (Scotts, Marysville, $\mathrm{OH}$ ), and grown for 3 months at $25^{\circ} \mathrm{C}$ under a 16 -h photoperiod of $50 \mu \mathrm{mol} \cdot \mathrm{m}^{-2} \cdot \mathrm{s}^{-1}$. Control plants, along with plants of six
$750 \mathrm{mg} \cdot \mathrm{L}^{-1}$
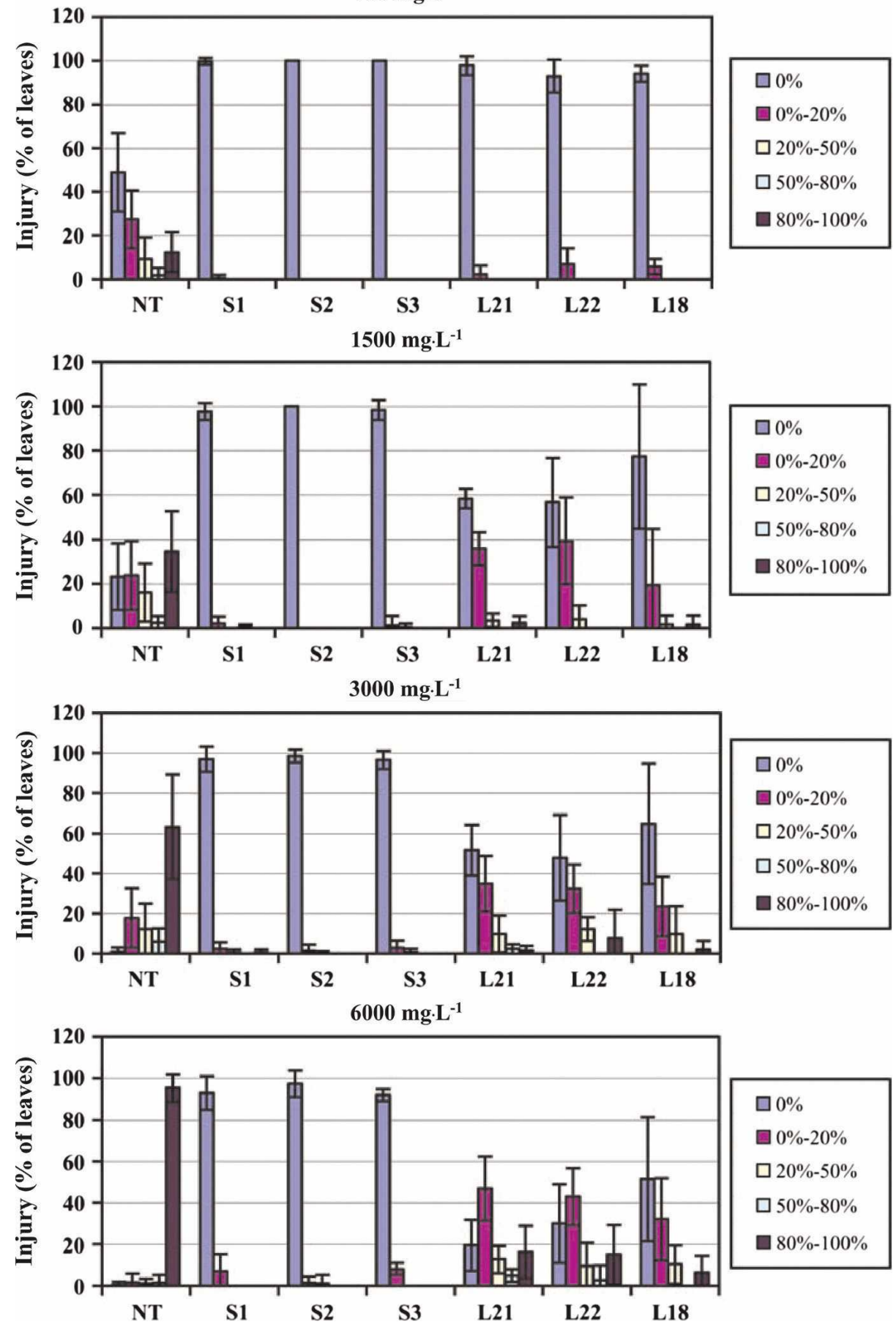

Fig. 6. Evaluation of herbicide resistance in 'Legacy' blueberry plants 2 weeks after application of four levels $\left(750,1500,3000\right.$, and $\left.6000 \mathrm{mg} \cdot \mathrm{L}^{-1}\right)$ of herbicide glufosinate under controlled environmental conditions. Injury ratings, 0 to 4 are classified according to the percentages of injured area for individual leaves: $0=$ no injury, $1=$ $0 \%$ to $20 \%$ injury, $2=20 \%$ to $50 \%$ injury, $3=50 \%$ to $80 \%$ injury, and $4=80 \%$ to $100 \%$ injury. NT $=$ nontransgenic blueberry; S1, S2, and S3 = transgenic events each with a single copy of the 35 S: :bar; L18, L21, and $\mathrm{L} 22=$ transgenic events each with a single copy of the nos: $:$ bar. single-copy transgenic events, three new events with $35 \mathrm{~S}$ and three reported events with nos promoter (Song et al., 2007a), were evaluated. Nondamaged plants with 10 to 30 leaves were sprayed with five levels $\left(0,750,1500,3000\right.$, and $\left.6000 \mathrm{mg} \cdot \mathrm{L}^{-1}\right)$ of GS (Rely; Bayer CropScience, Research Triangle Park, NC), respectively, using a track sprayer. The sprayed plants were subsequently grown under the same environmental conditions 
as described above. Herbicide injury to sprayed plants was recorded after 2 weeks by scoring all of the sprayed leaves of each plant, excluding three most newly emerging leaves. Each leaf was scored from 0 to 4 according to the percentage of leaf area with visible injury: $0=$ no injury, $1=$ $0 \%$ to $20 \%$ injury, $2=20 \%$ to $50 \%$ injury, $3=50 \%$ to $80 \%$ injury, and $4=80 \%$ to $100 \%$ injury.

These experiments were conducted using a completely randomized design with six plants as replications for each treatment. The experiments were performed twice.

Herbicide RESISTANCE IN FIELD PLANTS. Field trials were performed on four previously reported transgenic events with the nos::bar, of which L21, L22, and L18 each has a single copy of the nos::bar and L25 has three copies of the nos::bar (Song et al., 2007a). One-year-old plants, six for each transgenic event as well as four non transgenic plants, were sprayed on 8 Aug. 2006 with herbicide GS at $750 \mathrm{mg} \cdot \mathrm{L}^{-1}$. Additionally, two plants for each of the transgenic and nontransgenic events were sprayed with water. Herbicide injury to sprayed plants was recorded after 3 weeks. Two branches per plant, each with 10 to 20 leaves, were randomly selected and each leaf on the selected branches was scored as above from 0 to 4 . No field trials were conducted on transgenic plants with $35 S: \because b a r$ due to the lack of permission from the USDA-Animal and Plant Health Inspection Service.

\section{Results}

TRANSFORMATION AND REGENERATION. GS-resistant shoots emerged from $A$. tumefaciens-inoculated leaf explants after transformation with all of the four constructs, nos::bar, 35S::bar, (Aocs) ${ }_{3}$ AmasPmas::bar, and $34 S::$ bar. However, not every GS-resistant shoot showing resistance to $0.1 \mathrm{mg} \cdot \mathrm{L}^{-1} \mathrm{GS}$ proliferated on medium containing $0.5 \mathrm{mg} \cdot \mathrm{L}^{-1} \mathrm{GS}$. Only 16 individual transgenic events with $35 S: \because$ bar and three events with $34 S::$ bar proliferated on the medium containing $0.5 \mathrm{mg} \cdot \mathrm{L}^{-1} \mathrm{GS}$, whereas no shoots showed resistance to $0.5 \mathrm{mg} \cdot \mathrm{L}^{-1}$ GS after transformation with (Aocs) ${ }_{3}$ AmasPmas: $:$ bar (Table 1). All of the 19 transgenic events were verified to be positive by PCR amplification of the barcoding region (data not shown). The 35S::bar and the nos::bar produced higher herbicide resistance (GS at $0.5 \mathrm{mg} \cdot \mathrm{L}^{-1}$ ) in shoots than the (Aocs) ${ }_{3}$ AmasPmas::bar or the $34 S::$ bar during the

$\mathbf{B}$
A Before application
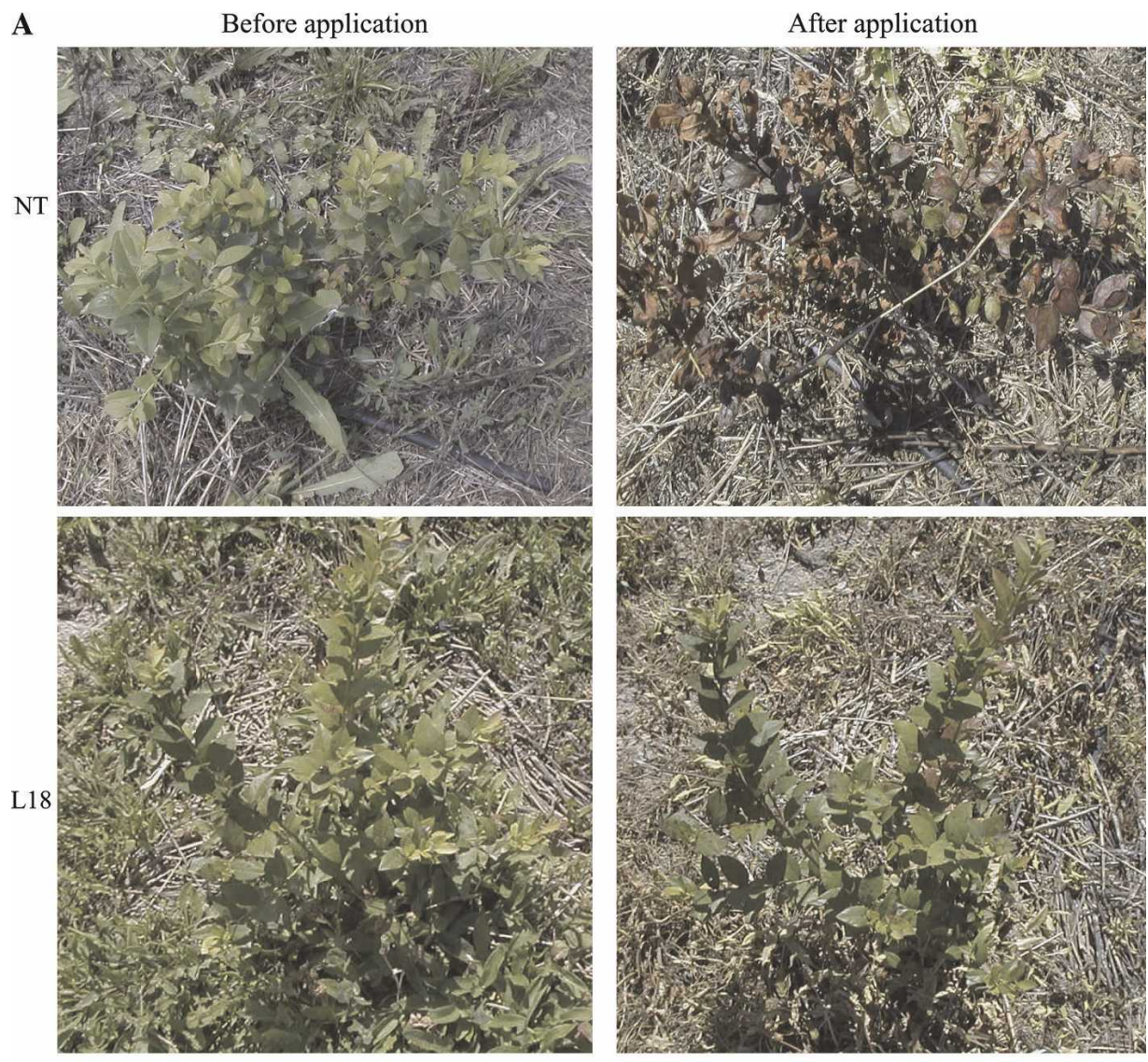

ig. 7. Response of field grown plants of 'Legacy' blueberry 2 weeks after application of herbicide glufosinate at $750 \mathrm{mg} \cdot \mathrm{L}^{-1}$ to the foliage. (A) Response of plants to herbicide. (B) Field of transgenic blueberry plants. NT-spray $=$ nontransgenic plants sprayed with herbicide; L21, L22, and L18 = transgenic events each with a single-copy of the nos: :bar; L25 $=$ a transgenic event with three copies of the nos: :bar.

selection step, indicating that the promoter of a selectable marker gene is important for efficient production of transgenic plants.

All 16 transgenic plants with $35 S::$ bar appeared similar with no obvious differences compared with the nontransformed plant. Of the three transgenic events with $34 S:: b a r$, rooted plants of one event appeared morphologically normal; in contrast, plants of the other two events had shortened internodes or reduced apical dominance.

CR ASSAY. We previously found that the CR assay was a reliable method to identify nos::bar-expressing transgenic blueberry shoots (Song et al., 2007a). Similarly, nontransgenic shoots were sensitive to GS in this study. They became necrotic 
and led to the red-orange color of the CR assay medium (Fig. 2). In contrast, transgenic shoots of three events (S1, S2, and S3) with $35 S::$ bar, one representative event with nos::bar, and one event with $34 S: \because$ bar continued normal growth and medium acidification, resulting in the yellowing of the assay medium over a 2-week period (Fig. 2).

SOUTHERN BLOT ANALYSIS AND PAT ASSAY. Southern hybridization confirmed stable integration of bar in all four independent transgenic events analyzed, including three with $35 S: \because b a r$ and one with $34 S: \because b a r$. One band was observed for each, whereas no signal was detected in the nontransgenic plant, as expected (Fig. 3). Because Bam HI is a unique cleavage site in the T-DNA region in vectors $35 S: \because$ bar and $34 S: \because$ bar (Fig. 1), the variation in the band pattern amongst transgenic events most likely represents a single copy of randomly inserted TDNA. This supports our previous observation that mostly low copy number transgenic plants are generated using $A$. tumefaciens-mediated transformation (Song and Sink, 2004).

$35 S::$ bar or $34 S: \because$ bar yielded active PAT in all of the four Southern-confirmed transgenic events. The PAT metabolically detoxified GS and produced an inactive product, $N$-acetyl-GS; in contrast, $N$-acetyl-GS was not detected in nontransgenic plants (Fig. 4).

HERBICIDE RESISTANCE IN PLANTS GROWN UNDER CONTROLLED ENVIRONMENTAL CONDITIONS. Due to the high sensitivity of blueberry leaves to GS, herbicide injury symptoms were initially observed on transgenic and nontransgenic plants $2 \mathrm{~d}$ after application of herbicide at all rates as red spots or red areas on leaves. On the nontransgenic plants, the initial moderate injury symptoms developed into extensive leaf necrosis, whereas most of the injury symptoms disappeared on transgenic plant leaves (Fig. 5). At high levels GS (1500, 3000, and $\left.6000 \mathrm{mg} \cdot \mathrm{L}^{-1}\right)$, transgenic plants with $35 \mathrm{~S}: \because$ bar showed less herbicide damage than those of with nos::bar (Fig. 5).

The data on final damage to the leaves indicated that transgenic plants with $35 S: \because$ bar or nos::bar showed much higher resistance to the herbicide than nontransgenic plants (Fig. 6). In addition, at high-dose GS (1500, 3000, and 6000 $\left.\mathrm{mg} \cdot \mathrm{L}^{-1}\right)$, transgenic plants expressing 35 S: :bar had higher percentages of nondamaged leaves than those expressing nos:: bar. The widest variations in herbicide resistance were

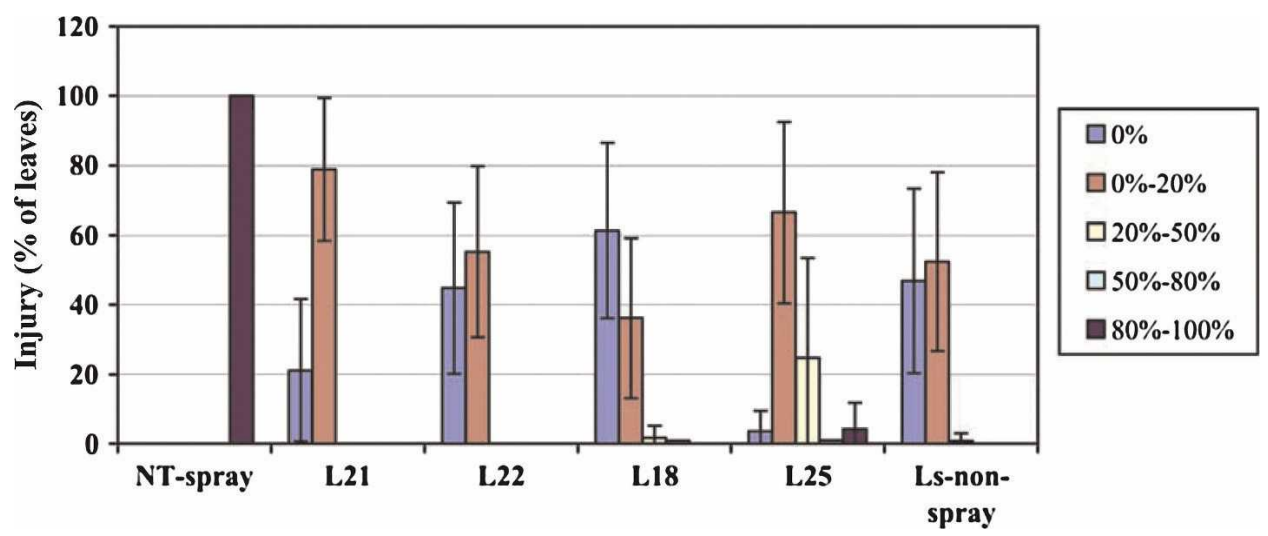

Fig. 8. Evaluation of herbicide resistance in field grown plants of 'Legacy' blueberry 2 weeks after application of herbicide glufosinate at $750 \mathrm{mg} \cdot \mathrm{L}^{-1}$. Sprayed leaves in two randomly selected branches for each plant were scored. Injury ratings, 0 to 4 are classified according to the percentages of injured area for individual leaves: $0=$ no injury, $1=0 \%$ to $20 \%$ injury, $2=20 \%$ to $50 \%$ injury, $3=50 \%$ to $80 \%$ injury, and $4=80 \%$ to $100 \%$ injury. NTspray $=$ nontransgenic plants sprayed with herbicide; L21, L22, and L18 = transgenic events each with a singlecopy of the nos: :bar; L $25=$ a transgenic event with three copies of the nos: $:$ bar; L-control $=$ two nonsprayed plants for each event of L21, L22, L18, and L25. observed at GS $6000 \mathrm{mg} \cdot \mathrm{L}^{-1}$, in which nontransgenic plants were seriously damaged and were dying, whereas plants of all three transgenic events with the nos::bar (L18, L21, and L22) remained alive but had $20 \%$ to $50 \%$ nondamaged leaves, and transgenic plants of all three events with the $35 S:: \operatorname{bar}(\mathrm{S} 1, \mathrm{~S} 2$, and S3) showed little damage with $92 \%$ to $97 \%$ nondamaged leaves (Fig. 6).

Herbicide resistance of field-grown plants. One day after the application of $750 \mathrm{mg} \cdot \mathrm{L}^{-1} \mathrm{GS}$, nontransgenic and transgenic leaves of field-grown plants exhibited herbicide injury symptoms as red spots. Subsequently, the red areas in nontransgenic leaves became necrotic, whereas the transgenic leaves returned to normal green. Two weeks after spraying with GS at $750 \mathrm{mg} \cdot \mathrm{L}^{-1}$, nontransgenic plants died, as did the surrounding weeds (Fig. 7). Plants of all the four transgenic events survived, confirming herbicide resistance in barexpressing plants (Fig. 7).

Quantitative analyses of scores confirmed herbicide resistance in transgenic plants (Fig. 8). In addition, field-grown blueberry plants showed greater sensitivity to GS than those grown under controlled environmental conditions (Fig. 8). There were no nondamaged mature leaves on nontransgenic plants 2 weeks after herbicide application. In contrast, the percentage of nondamaged leaves in transgenic plants sprayed with herbicide GS at $750 \mathrm{mg} \cdot \mathrm{L}^{-1}$ were $4 \%$ for $\mathrm{L} 25,21 \%$ for L $21,45 \%$ for L22, and $61 \%$ for L18, respectively. GS at 750 $\mathrm{mg} \cdot \mathrm{L}^{-1}$ caused little damage to plants of the two most highly resistant events (L18 and L22) compared with the watersprayed transgenic plants that had about $50 \%$ nondamaged leaves (Fig. 8), indicating adequate expression of nos::bar for commercial application.

\section{Discussion}

As one of the three current, major selectable marker genes (Miki and McHugh, 2004), bar is also a desirable herbicideresistance trait in crop plants. Many factors, such as promoters, culture conditions, and metabolic status of plant tissue, have impact on expression of bar, and thus correspondingly affect selection of transgenic tissues or subsequent level of herbicide resistance in the transgenic plants (De Block et al., 1995; Li et al., 2001).

Constitutive and inducible promoters have previously been used successfully to drive the bar gene (De Block et al., 1995; Li et al., 2001). Transformation with (Aocs) ${ }_{3}$ AmasPmas::bar versus nos::bar in peppermint (Mentha $\times$ piperita L. cv. Black Mitcham) yielded no significant difference in transformation frequency ( $\mathrm{Li}$ et al., 2001). In this study, when bar genes driven by four different promoters were tested for production of transgenic blueberry plants, expression of bar at in vitro stages was influenced by the promoter (Table 1). The (Aocs) ${ }_{3} \mathrm{~A}-$ masPmas promoter was previously shown to successfully drive $\beta$-glucuronidase expression in transgenic blueberry plants (Song and Sink, 
2004). In this study, low activity of the promoter under in vitro conditions or misplacement of promoter region during gene construction or transformation might be responsible for the failure in production of transgenic shoots with (Aocs) ${ }_{3}$ Amas $P$ mas: :bar. The (Aocs) ${ }_{3}$ AmasPmas: $:$ bar was more likely than the nos::bar to yield higher herbicide resistance in peppermint $(\mathrm{Li}$ et al., 2001). We found that the 35S::bar and the nos::bar had similar transformation frequencies; however, the plants expressing the $35 S: \because b a r$ showed higher herbicide resistance than those expressing the nos::bar under controlled environmental conditions (Figs. 5 and 6). Therefore, the transformation frequency with different promoters is not a good criterion for predicting herbicide resistance in bar-expressing plants.

Using single-copy transgenic plants, we demonstrated that herbicide resistance in blueberry plants can be strengthened by using better promoters. Under controlled environmental conditions, the nos or the $35 \mathrm{~S}$ promoter is efficient to direct expression of the bar in blueberry plants (Figs. 5 and 6). Sensitivity of nontransgenic and transgenic plants to herbicide is also influenced by plant age or environmental conditions (Figs. 6 and 8). Unlike the application of nonselective, systemic herbicides in commercial fields where contact with the blueberry foliage is avoided, in our field trials, the nos::bar-expressing plants were sprayed directly with herbicide. Because bar-expressing plants quickly recovered after GS application, this type of expression may work well in the commercial industry. In addition, a directed spray that might hit lower leaves and the canes but not drench the plant with glufosinate would be better as it would not set plants back as far and reduce recovery time. Additional field trials are still needed to evaluate those bar-expressing plants, in particular, how the transgene affects fruit quality and yield.

In summary, this article demonstrates that when the bar gene is used as a selectable marker, transformation frequency is influenced by promoter strength, that herbicide resistance in blueberry plants can be enhanced by using stronger promoters, and that it is possible to engineer blueberry plants with resistance to herbicide using the bar gene.

\section{Literature Cited}

An, G., P.R. Ebert, A. Mitra, and S.B. Ha. 1988. Binary vectors, p. A3:1-19. In: S.B. Gelvin and R.A. Schilperoot (eds). Plant molecular biology manual. Kluwer, Dordrecht, The Netherlands.

Becker, D., E. Kemper, J. Schell, and R. Masterson. 1992. New plant binary vectors with selectable markers located proximal to the left T-DNA border. Plant Mol. Biol. 20:1195-1197.

Cao, X., I. Fordham, L. Douglass, and F.A. Hammerschlag. 2003. Sucrose level influences micropropagation and gene delivery into leaves from in vitro propagated highbush blueberry shoots. Plant Cell Tissue Organ Cult. 75:255-259.

Cao, X., Q. Liu, L.J. Rowland, and F.A. Hammerschlag. 1998. GUS expression in blueberry (Vaccinium spp.): Factors influencing Agrobacterium-mediated gene transfer efficiency. Plant Cell Rpt. 18:266-270. Castle, L.A., D.L. Siehl, R. Gorton, P.A. Patten, Y.H. Chen, S. Bertain, H.-J. Cho, N. Duck, J. Wong, D. Liu, and M.W. Lassner. 2004. Discovery and directed evolution of a glyphosate tolerance gene. Science 304:1151-1154.

Conner, A.M., J.J. Luby, and C.B.S. Tong. 2002. Variability in antioxidant activity in blueberry and correlations among different antioxidant assays. J. Amer. Soc. Hort. Sci. 127:238-244.

De Block, M., J. Botterman, M. Vandewiele, J. Dockx, C. Thoen, V. Gosselé, C. Thompson, M. Van Montagu, and J. Leemans. 1987. Engineering herbicide resistance in plants by expression of a detoxifying enzyme. EMBO J. 6:2513-2518.
De Block, M., A. De Sonville, and D. Debrouwer. 1995. The selection mechanism of phosphinothricin is influenced by the metabolic status of the tissue. Planta 197:619-626.

Dhanaraj, A.L., N.W. Alkharouf, H.S. Beard, I.B. Chouikha, B.F. Matthews, H. Wei, R. Arora, and L.J. Rowland. 2007. Major differences observed in transcript profiles of blueberry during cold acclimation under field and cold room conditions. Planta 225:735-751.

Dhanaraj, A.L., J.P. Slovin, and L.J. Rowland. 2004. Analysis of gene expression associated with cold acclimation in blueberry floral buds using expressed sequence tags. Plant Sci. 166:863-872.

Doyle, J. and J. Doyle. 1987. A rapid DNA isolation procedure for small quantities of fresh leaf tissue. Phytochem. Bul. 19:11-15.

Ehlenfeldt, M.K. and R.L. Prior. 2001. Oxygen radical absorbance capacity (ORAC) and phenolic and anthocyanin concentrations in fruit and leaf tissues of highbush blueberry. J. Agr. Food Chem. 49:2222-2227.

Graham, J., K. Greig, and R.J. McNicol. 1996. Transformation of blueberry without antibiotic selection. Ann. Appl. Biol. 128:557-564.

Hood, E.E., S.B. Gelvin, L.S. Melchers, and A. Hoekema. 1993. New Agrobacterium helper plasmids for gene transfer to plants. Transgenic Res. 2:208-218.

James, C. 2007. Global status of commercialized biotech/GM crops: 2007. Int. Serv. Acquisition Agri-biotech Applications (ISAAA) Brief No. 37. ISAAA, Ithaca, NY.

Li, X., Z. Gong, H. Koiwa, X. Niu, J. Espartero, X. Zhu, P. Veronese, B. Ruggiero, R.A. Bressan, S.C. Weller, and M. Hasegawa. 2001. Bar-expressing peppermint (Mentha $\times$ piperita L. var. Black Mitcham) plants are highly resistant to the glufosinate herbicide Liberty. Mol. Breed. 8:109-118.

Miki, B. and S. McHugh. 2004. Selectable marker genes in transgenic plants: Applications, alternatives and biosafety. J. Biotechnol. 107:193-232.

Naik, D., A.L. Dhanaraj, R. Arora, and L.J. Rowland. 2007. Identification of genes associated with cold acclimation in blueberry (Vaccinium corymbosum L.) using a subtractive hybridization approach. Plant Sci. 173:213-222.

Ni, M., D. Cui, J. Einstein, S. Narasimhulu, C.E. Vergara, and S.B. Gelvin. 1995. Strength and tissue specificity of chimeric promoters derived from the octopine and mannopine synthase genes. Plant J. 7:661-676.

Polashock, J. and N. Vorsa. 2002. Cranberry transformation and regeneration, p. 383-396. In: G.G. Khachatourians, A. McHughen, R. Scorza, W.-K Nip, and Y.-H. Hui (eds.). Transgenic plants and crops. Marcel Dekker, New York.

Ratnaparkhe, M.B. 2007. Blueberry, p. 217-227. In: C. Kole (ed.). Genome mapping and molecular breeding in plants, Volume 4: Fruits and nuts. Springer-Verlag, Heidelberg/Berlin, Germany.

Rowland, L.J. 1990. Susceptibility of blueberry to infection by Agrobacterium tumefaciens.. HortScience 25:1659.

Song, G.-Q. and K.C. Sink. 2004. Agrobacterium tumefaciens-mediated transformation of blueberry (Vaccinium corymbosum L.). Plant Cell Rpt. 23:475-484.

Song, G.-Q. and K.C. Sink. 2005. Plant regeneration and transformation of blueberry. Recent Res. Dev. Genet. Breeding 2:190-200.

Song, G.-Q. and K.C. Sink. 2006. Blueberry (Vaccinium corymbosum L.), p. 263-272. In: K. Wang (ed). Agrobacterium protocols. 2nd ed. Humana, Totowa, NJ.

Song, G.-Q., H. Honda, and K. Yamaguchi. 2007b. Expression of a rice $C A B$ promoter in sweetpotato plants. J. Amer. Soc. Hort. Sci. 132:551-556.

Song, G.-Q., R.A. Roggers, K.C. Sink, M. Particka, and B. Zandstra. 2007a. Production of herbicide-resistant highbush blueberry 'Legacy' by Agrobacterium-mediated transformation of the bar gene. Acta Hort. 738:397-407.

U.S. Department of Agriculture. 2007. 2006 blueberry statistics. U.S. Dept. Agr., Natl. Agr. Stat. Serv., Trenton, NJ.

Wilmink, A., B.C.E. Van de Ven, and J.J.M. Dons. 1995. Activity of constitutive promoters in various species from the Liliaceae. Plant Mol. Biol. 28:949-955. 